\title{
Recurrent wheezing in the preschool child
}

\author{
W. LENNEY AND A. D. MILNER \\ From the Department of Child Health, University Hospital and Medical School, Nottingham
}

SUMMARY The bronchoconstrictor response to exercise was measured in 29 healthy children and in 23 children with recurrent wheezing attacks, using the Wright low-range peak flow meter and a modification of the forced oscillation technique. None of the healthy children showed significant change in airflow obstruction after a 6-minute run, whereas 20 of the 23 wheezy children showed a mean rise in total respiratory resistance of $65.5 \%$. All 23 children showed a fall in airflow obstruction after inhaling salbutamol solution.

It is well known that children who develop attacks of coughing and wheezing in the early years of life tend to lose their symptoms in later childhood. As these attacks are often associated with upper respiratory tract infections, a diagnosis of recurrent wheezy bronchitis is frequently made. However, some children continue to wheeze intermittently and are eventually diagnosed as having asthma. In children under the age of one year the picture of recurrent wheezy bronchitis differs from that of childhood asthma on two counts. Firstly, infection often appears to be the sole precipitating factor, and secondly these attacks do not respond to standard bronchodilator therapy (Phelan and Williams, 1969; Radford, 1975; Rutter et al., 1975). After the age of 3 years the two conditions merge and Williams and McNicol (1969) were unable to divide them into separate entities. Despite this, there is still much confusion about the underlying pathology in wheezy preschool children and antibiotics are often prescribed in situations where, if these children do have asthma, bronchodilator therapy would be more appropriate. Very few lung function studies have been carried out on this important group of children. This is partly because they are at a difficult age to study but also because suitable techniques have only recently become available (Hatch and Milner, 1974).

In the older child numerous studies have shown that the asthmatic child can be distinguished from his healthy control by the degree of bronchoconstriction induced by standardised exercise tests (Jones et al., 1962; Godfrey et al., 1973; Godfrey, 1974). We decided it would be both interesting and useful to apply these techniques to children between

Received 8 November 1977 the ages of 3 and 5 years. We measured airflow resistance using the Wright low range peak flow meter (Wright and McKerrow, 1959) and total respiratory resistance $\left(R_{T}\right)$ using the recently developed forced oscillation technique (DuBois et al., 1956; Cogswell, 1973) in an attempt to assess whether preschool children with recurrent wheezing attacks did have abnormal bronchial lability similar to that seen in the older asthmatic child.

Subjects. Control data were obtained from 29 children (14 boys, 15 girls) attending two day nurseries in Nottingham. Their ages ranged from 2.8 to 4.9 (mean 3.5 years). None had had a previous wheezing episode and there was no history of asthma in first-degree relatives. The 23 children with recurrent wheezing episodes (16 boys, 7 girls) were all attending paediatric outpatient clinics in Nottingham. Their ages ranged from $3 \cdot 1$ to $5 \cdot 2$ years (mean 3.8 years). 8 of the children had eczema and 17 had a family history of asthma. All the children had had recurrent wheezing attacks for between 9 and 38 months. 5 had required admission to hospital and 15 had received at least one course of antibiotics. 8 had never received bronchodilator therapy. The children were selected on the grounds that they were between the ages of $2 \cdot 8$ and $5 \cdot 3$ years and had recurrent attacks of coughing and wheezing leading to admission to hospital or referral to the paediatric outpatient department. All therapy was stopped for at least 12 hours before exercise testing. All the children were examined immediately before the run. All were physically well, showing no clinical evidence of airways obstruction. Repeat tests were carried out within 2 weeks of the initial study on 6 of the healthy children and 9 of the children with recurrent wheezing episodes. 


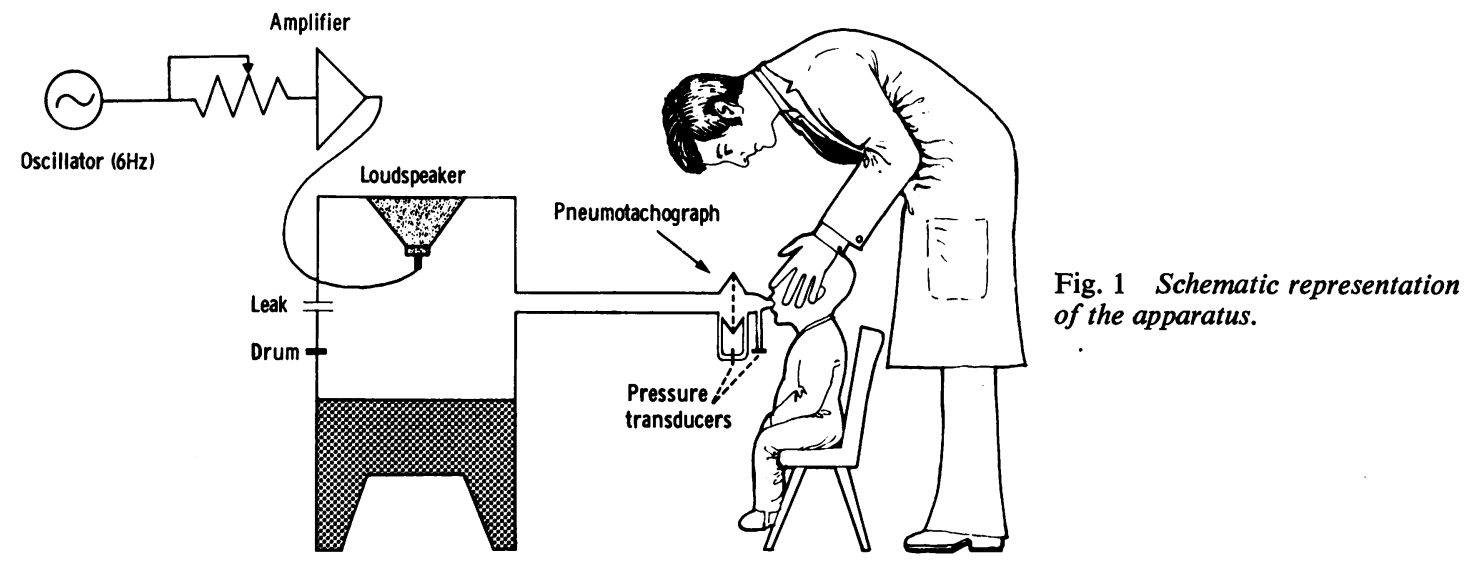

\section{Method}

Apparatus. Two systems were used to assess lung function.

(i) Wright's low-range peak flow meter. This records over the 20-200 1/min range, has previously been used in children down to the age of $2 \frac{1}{2}$ years and shown to provide reproducible results (Milner and Ingram, 1970).

(ii) Forced oscillation technique. Based on the principle that when a sine-wave flow oscillation is applied to the respiratory system at the resonant frequency, the impedance to the oscillatory flow is due solely to the total respiratory resistance $\left(R_{T}\right)$, since at $r \in$ sonance the elastic and inertial impedance are of equal magnitude and opposite in sign. The apparatus used was similar to that described by Cogswell (1973) (see Fig. 1). The child sat on a chair breathing quietly through a gauze pneumotachograph (Mercury Electronics F300L flow head) which was connected to a 120 litre rectangular wooden box via a $3 \mathrm{~cm}$-bore flexible tube. The pressure gradients across the pneumotachograph (airflow) and the mouth pressure fluctuations were measured by identical, sensitive differential transducers (SE Labs 4009). The outputs from the transducers were relayed through conditioning and amplification systems (SE Labs 905) to an ultraviolet-sensitive recorder (SE Labs 3006). The generator (Griffin 394), fed through a 20 watt oscillations were generated by a sine-wave output audio amplifier (Vortexion) to a 13 inch sandwich cone loudspeaker (Leake). The loudspeaker was mounted on the inner wall of the rectangular box. A $15 \mathrm{~cm}$ hole was cut into the wall overlying the cone to prevent mechanical damping.
The gain on the amplifier was adjusted to produce the maximum flow deflection which could be achieved without obvious distortion of the sine-wave when the $3 \mathrm{~cm}$ flexible tube was totally excluded. This resulted in pressure fluctuations of approximately $\pm 0 \cdot 1 \mathrm{kPa}\left( \pm 1 \mathrm{cmH}_{2} \mathrm{O}\right)$ within the system. The resistance was calculated by dividing the induced pressure oscillation by the flow oscillation. Previous work with this system had shown that as the maximum pressure generated by the loudspeaker was $0 \cdot 2 \mathrm{kPa}\left(2 \mathrm{cmH}_{2} \mathrm{O}\right)$, an increase in resistance led to a fall in the flow oscillation, so that results became progressively less accurate. Any attempt to increase accuracy by increasing the gain on the flow trace also increased the slow oscillations of the child's spontaneous breathing pattern, taking the trace off the paper at the extremes of flow. To overcome this we incorporated a band-pass filter which damps any signal below $2 \mathrm{~Hz}$ to less than $5 \%$, leaving the signal at $6 \mathrm{~Hz}$ undamped. This effectively eliminated the child's own flow pattern except at the beginning of inspiration and expiration, where rapid components of the breath broke through the filter and produced easily recognisable artefacts (Fig. 2). Once the filter was turned on the gain could be increased, allowing improved accuracy.

The incorporation of the filter inevitably induced a phase shift in the sine-wave flow oscillation, which made it impossible to base the calculations of resistance on the pressure gradient between the extremes of flow oscillation as described by Goldman et al. (1970) and Cogswell (1973). However, previous experience has shown that calculations carried out in this manner progressively underestimate the resistance as airflow obstruction increases, so that at very high resistances negative values can be obtained due to extreme phase shift between the flow and the mouth pressure. In this study we elected to use the 

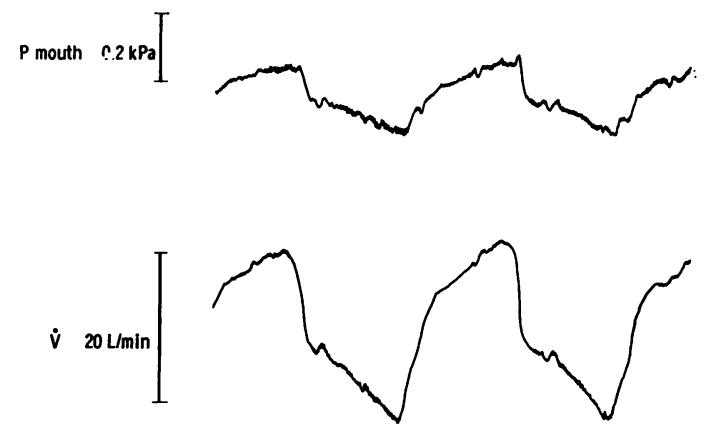

(a)

Fig. 2 Traces of mouth pressure ( $P$ mouth) and mouth flow $(\dot{V})$ inspiration producing an upward deflection: (a) with the oscillator off, showing the pattern produced by the child's breathing alone; (b) with the $6 \mathrm{~Hz}$ oscillations superimposed on the child's breathing; (c) with the band pass filter in circuit, effectively removing the flow component produced by the child's tidal breathing. The gain has been increased to improve accuracy. At the end tidal points of the breathing cycle the change in flow rate is rapid enough to get through the filter producing artefacts (arrows).

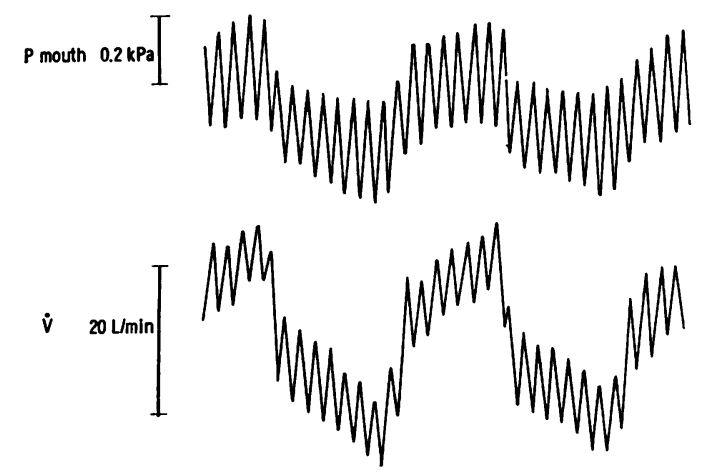

(b)

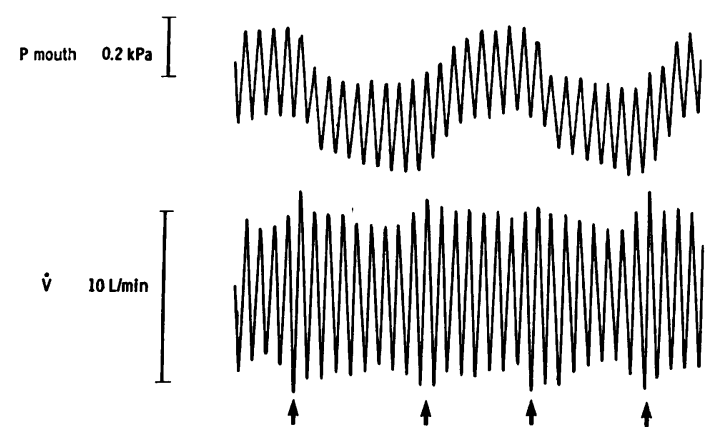

(c) extremes of the pressure oscillations as well as the flow oscillations in our calculations. The midexpiration part of the trace was selected for analysis since this was the most stable part of the record. At least three sequential breaths were used in each measurement. In this way each $R_{r}$ result was derived from at least 12 sine-wave oscillations.

At the end of each session the mouth pressure was calibrated against a water column and the pneumotachograph against a rotameter. The $63 \%$ rise time of both channels was $4 \mathrm{~ms}$, giving a $3 \mathrm{db}$ octave cut off at $39.8 \mathrm{~Hz}$. The band pass filter resulted in a phase shift of $90^{\circ}$.

Procedure. On arrival in the laboratory the peak expiratory flow rate (PEFR) was determined using the Wright low-range peak flow meter. After explanation and practice the best of three consecutive flows was recorded. $R_{T}$ was measured with the child seated. His cheeks were stabilised and the nose occluded, either by his own hands or by those of one of the investigators. Initially some of the children tended to close their glottis, producing an artefactual record. This was overcome by encouraging them to take quiet deep breaths. At least three complete respiratory cycles were then recorded. Measurements of PEFR and $R_{T}$ were then repeated 20 minutes later and again at 2, 5, 10, 20, and 25 minutes after running along an indoor corridor for 6 minutes. As these children were very young, it was necessary for them to be accompanied on the run by one of us (W.L.). On all occasions the child's heart rate exceeded $170 / \mathrm{min}$ at the end of the run. The children with recurrent wheezy bronchitis inhaled $1 \mathrm{ml} 0.5 \%$ salbutamol respirator solution diluted in $1 \mathrm{ml}$ sterile water from the face mask of a commercially-available nebuliser (Pari). Measurements of $R_{\mathrm{T}}$ and PEFR were repeated 2 and 5 minutes after nebulisation.

\section{Results}

The lung functions results obtained on the 29 healthy children before and after the 6-minute run are shown in Fig. 3. The initial PEFR value ranged from 85 to $165 \mathrm{l} / \mathrm{min}$ (mean $123 \mathrm{l} / \mathrm{min}$ ) and the $R_{\mathrm{T}}$ from 0.7 to $1.35 \mathrm{kPa} / 1$ per $\mathrm{s}\left(7.2\right.$ to $13.9 \mathrm{cmH}_{2} \mathrm{O} / 1$ per $\left.\mathrm{s}\right)$, mean $1 \cdot 1 \mathrm{kPa} / 1$ per $\mathrm{s}\left(11 \cdot 3 \mathrm{cmH}_{2} \mathrm{O} / 1 \mathrm{per} \mathrm{s}\right)$. All fell within $\pm 2 \mathrm{SD}$ of the mean values predicted from previously published normal data (Milner and Ingram, 1970; Cogswell, 1973). The exercise had no significant effect on either PEFR or $R_{T}$ over the period studied. All but one of these children showed a drop in PEFR of less than $17 \%$ and all children had a rise of $R_{T}$ less than $15 \%$ of the base-line value. The coefficient of variation of the percentage 
change between the two prerun readings for PEFR was $11 \%$, and for the $R_{T} 9 \%$.
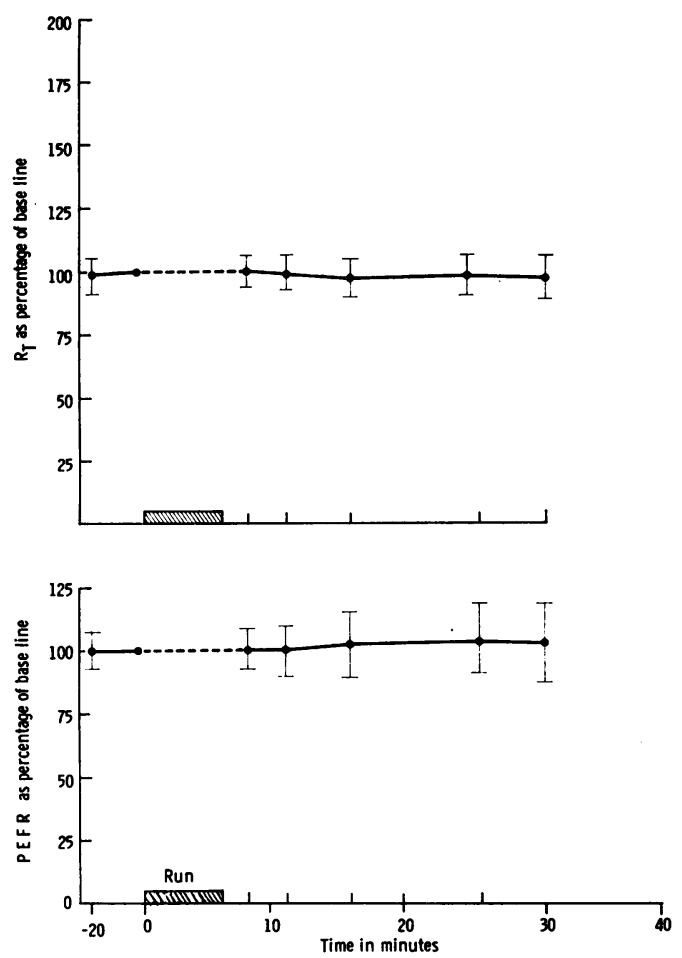

Fig. 3 Total respiratory resistance $\left(R_{T}\right)$ and peak expiratory flow rate (PEFR) (mean for group $\pm 1 S D$ ) before and after a 6-minute run in 29 healthy children. The results are expressed as a percentage of the readings obtained immediately before the run.

Three children with recurrent wheezing were unable to use the peak flow meter satisfactorily but could use the oscillator. The initial PEFR readings of the remaining children ranged from 60 to 150 $1 /$ min (mean $117 \mathrm{l} / \mathrm{min}$ ) and the $R_{\mathrm{T}}$ from 0.8 to $1.6 \mathrm{kPa} / 1$ per s $\left(8 \cdot 2-16.5 \mathrm{cmH}_{2} \mathrm{O} / 1\right.$ per s), mean $1.28 \mathrm{kPa} / 1$ per $\mathrm{s}\left(13.2 \mathrm{cmH}_{2} \mathrm{O} / 1\right.$ per s). 3 of the PEFR readings were below -2 SD and 6 of the $R_{r}$ readings above +2 SD of the mean values predicted from their heights (Milner and Ingram, 1970; Cogswell, 1973). Of the 20 children who could use the peak flow meter, all but 3 showed striking bronchoconstriction after exercise (Fig. 4), with a mean fall in PEFR of $39.2 \%$. All but one showed a peak fall in PEFR of greater than $20 \%$. The mean rise in PEFR after salbutamol was $29 \%$. All 23 children used the oscillator satisfatorily. 20 of these children showed exercise-induced bronchoconstriction with a mean peak rise in $R_{\mathrm{T}}$ of $65.6 \%$ after exercise, and all exceeded $31 \%$. The mean fall in $\mathbf{R}_{\mathrm{T}}$ after salbutamol was $33 \%$.
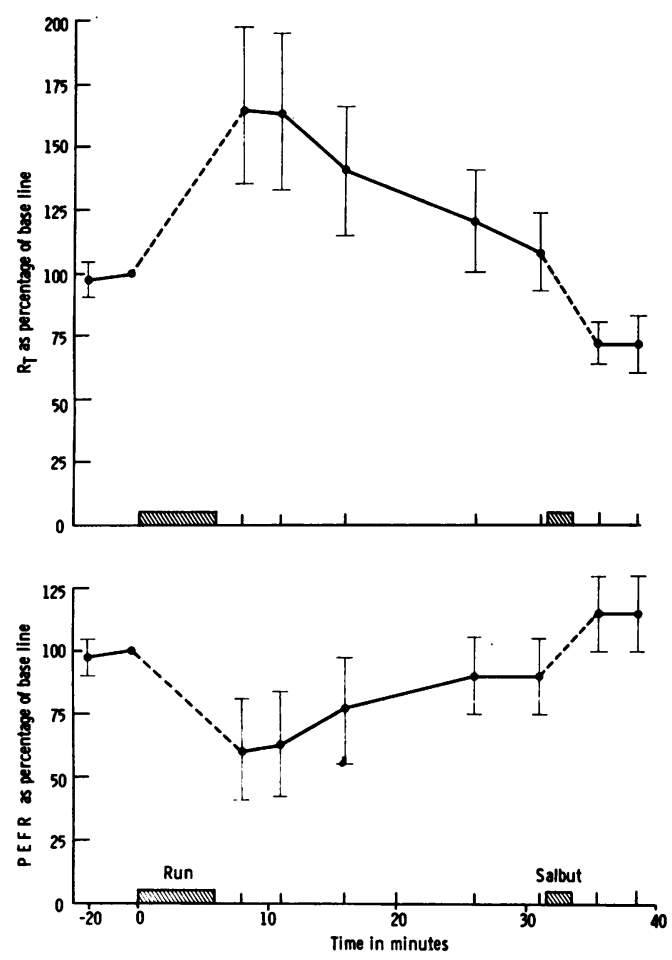

Fig. $4 R_{T}$ and PEFR (mean for group $\pm 1 S D$ ) before, after a 6-minute run, and also after inhalation of nebulised salbutamol, in a group of 20 children with recurrent wheezing. PEFR results are based on 17 children only as 3 were unable to use the peak flow meter satisfatorily.

Three children with recurrent wheezy attacks showed no apparent bronchoconstriction after exercise (Fig. 5). Their base-line data were similar to the other wheezy children and they showed a mean rise in PEFR of $12 \%$ and a mean fall in RT of $29 \%$ after the salbutamol inhalation.

Six healthy children showed a mean fall of $7 \%$ in PEFR and a mean rise in $R_{T}$ of $6 \cdot 2 \%$ on retesting. The 9 wheezy children we retested showed abnormal responses with a mean peak fall in PEFR of $36 \%$ and a mean peak rise in $R_{T}$ of $64 \%$. Although repeat results were still within the abnormal range, reproducibility. was poor, one child showing a rise in $R_{T}$ of $63 \%$ on the first occasion and $31 \%$ on the second. 2 of the 3 children with recurrent wheeze who did not exhibit exercise-induced bronchoconstriction were retested. Again no abnormal exercise lability could be detected, although salbutamol inhalation resulted in an increase in PEFR of $24 \%$ and $29 \%$ and a fall in $R_{T}$ of $34 \%$ and $40 \%$ respectively. 

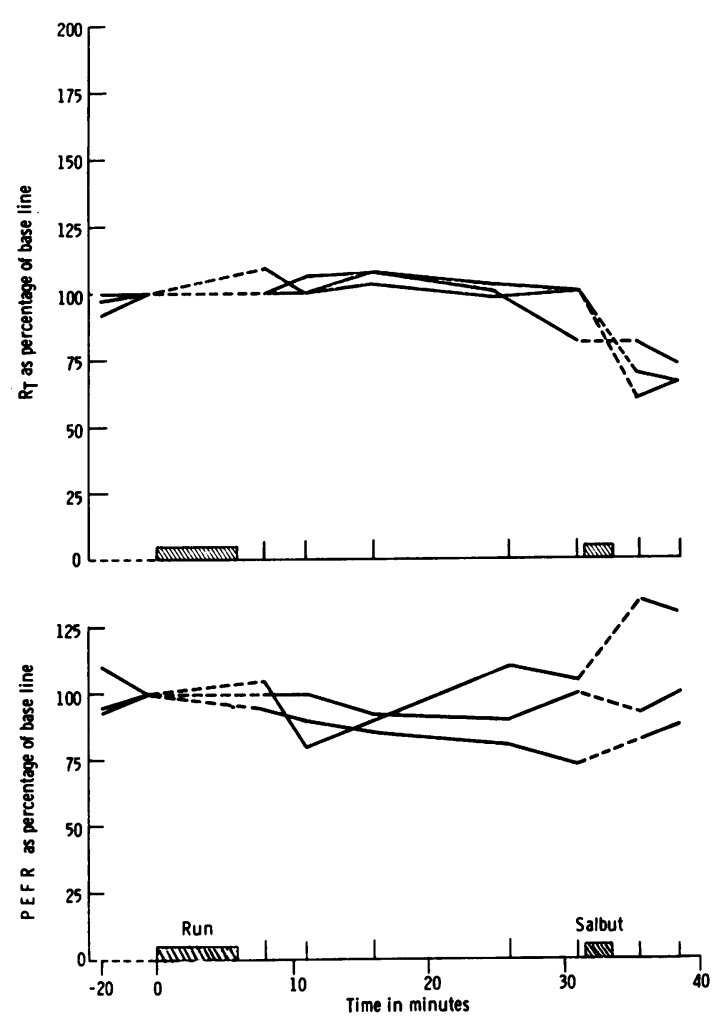

Fig. $5 R_{T}$ and PEFR before, after a 6-minute run, and after inhalation of nebulised salbutamol in the 3 children with recurrent wheezing who failed to exhibit exercise-induced bronchoconstriction. Results are expressed as a percentage of the readings obtained immediately before the run.

\section{Discussion}

These studies show the value of the forced oscillation technique in assessing changes in airflow obstruction in the preschool child. The reproducibility assessed by comparing the two prerun measurements in the healthy children was better using the oscillator than that obtained using the Wright low-range peak flow meter, $9 \%$ compared to $11 \%$. A correlation coefficient of 0.72 was obtained on 54 readings of PEFR and $R_{T}$ recorded on 6 of the children with recurrent wheezy attacks. Since the PEFR was measured during the forced expiratory manoeuvre, while the $R_{T}$ was recorded during quiet breathing, this correlation is acceptable. Our method for calculating $R_{T}$ is open to criticism since in the presence of airflow obstruction a phase shift occurred between the flow and the mouth oscillation, indicating that conditions of resonance no longer existed. We consider Goldman's modification
(Goldman et al., 1970) inappropriate in the presence of a high degree of airflow obstruction, since the respiratory system no longer has a single resonance frequency. Our measurements tended to over-read as airflow obstruction rose. As illustrated in this study, this flaw does not invalidate the technique as a method of detecting change.

The exercise studies were unsophisticated and relatively nonstandardised, as in this age group measurements of work done are most unlikely to be successful. However, we consider that a rise in heart rate to greater than 170 per minute indicated that these children had undergone a prolonged severe exercise. The results show that the majority $(87 \%)$ of the wheezy children between the ages of 3 and 5 years exhibit bronchial lability similar to that occurring in the older asthmatic child (Godfrey et al., 1973). In the 20 children who showed this phenomenon there was no overlap in $R_{T}$ between the healthy controls and their wheezy colleagues. Indeed, the maximum rise in $R_{T}$ in the healthy children of $15 \%$ was far lower than the minimum increase of $31 \%$ observed in the wheezy children. 3 of the children did not have this paettrn of exerciseinduced bronchospasm but they, like the other wheezy children, had a significant fall in $R_{T}$ after inhaling salbutamol, indicating that they too had abnormal bronchial lability.

The response to salbutamol, although the data were uncontrolled, was in itself interesting since this is to our knowledge the first time a response to bronchodilator therapy has been shown objectively in children under the age of 5 years. These data may be criticised on the grounds that the bronchoconstriction was still receding at the time salbutamol was given. However, the difference between the PEFR at 20 and 25 minutes postexercise was not significant ( $P>0.48)$, whereas the rise in PEFR after salbutamol was highly significant $(P<0 \cdot 0005)$. For the $R_{\mathrm{T}}$ data, $\mathrm{P}<\mathbf{0 . 0 2 5}$ at 20 to 25 minutes compared to $\mathbf{P}<0 \cdot 0005$ for the response to salbutamol.

Conclusions. (1) The large majority of children between the ages of 3 and 5 years with recurrent wheezing attacks have abnormal bronchial lability similar to that seen in the older asthmatic child. This supports Williams and McNicol's (1969) suggestion that these children represent one end of the asthma spectrum. (2) These children respond to bronchodilator therapy and it is therefore more likely to be helpful than courses of antibiotics. 8 of our children had apparently never been given bronchodilator therapy. (3) Exercise testing is of diagnostic value in the younger child and can be used to identify those with abnormal bronchial lability at least down to the age of 3 years. (4) The 
forced oscillation technique is valuable in assessing changes in airflow obstruction in young children.

We gratefully acknowledge financial support for this project from the Chest and Heart Association.

\section{References}

Cogswell, J. J. (1973). Forced oscillation technique for determination of resistance to breathing in childhood. Archives of Disease in Childhood, 48, 259-266.

DuBois, A. B., Brody, A. W., Lewis, D. H., and Burgess, B. F., Jr. (1956). Oscillation mechanics of lung and chest in man. Journal of Applied Physiology, 8, 587-594.

Godfrey, S. (1974). Exercise Testing in Children. Saunders, London.

Godfrey, S., Silverman, M., and Anderson, S. D. (1973). Problems of interpreting exercise induced asthma. Journal of Allergy and Clinical Immunology, 52, 199-209.

Goldman, M., Knudson, R. J., Mead, J., Peterson, N. Schwaber, J. R., and Wohl, M. E. (1970). Simplified measurement of respiratory resistance by forced oscillation. Journal of Applied Physiology, 28, 113-116.

Hatch, D. J., and Milner, A. D. (1974). The measurement of lung function in infants and children under five years of age. International Anaesthesiology Clinics, 12, No. 4, $37-59$.
Jones, R. S., Buston, M. H., and Wharton, M. J. (1962) The effect of exercise on ventilatory function in the child with asthma. British Journal of Diseases of the Chest, 56, 78-86.

Milner, A. D., and Ingram, D. (1970). Peak expiratory flow rates in children under 5 years of age. Archives of Disease in Childhood, 45, 780-782.

Phelan, P. D., and Williams, H. E. (1969). Studies of respiratory function in infants with recurrent asthmatic bronchitis. Australian Paediatric Journal, 5, 187-196.

Radford, M. (1975). Effect of salbutamol in infants with wheezy bronchitis. Archives of Disease in Childhood, 50, 535-538.

Rutter, N., Milner, A. D., and Hiller, E. J. (1975). Effect of bronchodilators on respiratory resistance in infants and young children with bronchiolitis and wheezy bronchitis. Archives of Disease in Childhood, 50, 719-722.

Williams, H. E., and McNicol, K. N. (1969). Prevalence, natural history and relationship of wheezy bronchitis and asthma in children. An epidemiological survey. British Medical Journal, 4, 321-325.

Wright, B. M., and McKerrow, C. B. (1959). Maximum forced expiratory flow rate as a measure of ventilatory capacity. British Medical Journal, 2, 1041-1046.

Correspondence to Dr A. D. Milner, Department of Child Health, University Hospital and Medical School, Clifton Boulevard, Nottingham NG7 2UH. 